\title{
Social Identification and Normative Conflict: When student and educator learning norms collide
}

\author{
Lillian Smyth ${ }^{a}$, Vritika Chandra ${ }^{c}$, Kenneth I. Mavor ${ }^{a, b}$ \\ ${ }^{a}$ Medical Education Unit, Australian National University, Canberra, Australia \\ ${ }^{b}$ School of Psychology and Neuroscience, University of St Andrews, Scotland. \\ ${ }^{c}$ Research School of Psychology, Australian National University, Canberra, Australia
}

Word count (exc figures, tables, abstract \& reference list): 6625

Corresponding Author:

Lillian Smyth

Medical Education Unit

ANU Medical School

Florey Building

54 Mills Road

The Australian National University

Acton, ACT, 2601

Email: Lillian.Smyth@anu.edu.au

This manuscript was accepted for publication in the Journal of Applied Social Psyhcology in January, 2018. This is the authors pre-press version. An early view copy can be found online at the publisher's website here:

http://onlinelibrary.wiley.com/doi/10.1111/jasp.12505/abstract 
Social Identification and Normative Conflict: 2 


\begin{abstract}
:
The current paper explores perceived norm conflict, social identification and learning approaches in the applied context of higher education. Research has established the influence of identification with fellow students, and their perceived norms, on student approaches to learning. However, in the current paper, we argue that this model is not entirely ecologically valid and that students are not the only source of normative influence in the study context. In this first step to unpack these complex normative influences, we examine the next mostproximal source of normative information- the educator. In essence, we explore the ways that the normative communications of a within-field educator can also influence student learning approaches and the ways these two sets of normative effects may interact. Testing a sample of undergraduate students at Australian universities, we explore how students resolve conflicting intragroup norm sources. Findings suggest that, in line with previous literature, stronger identification with the field of study is associated with deep learning approaches, and this effect is moderated by perceived student norms such that the valence of the study norms can undermine or accentuate this effect. Novel results unpacking the effects of normative conflict suggest that this moderation effect is only present when educator norms are ambiguous and that, in instances of clearly conflicting normative messages, the identification main effect prevails. The implications and applications are discussed.
\end{abstract}

Keywords: social identity; learning approach; norms; normative conflict; higher education; intragroup behaviour; social influence Word Count: 5750 (excl abstract, ref list \& tables) 
Social Identification and Normative Conflict: 4

\section{Social Identification and Normative Conflict: When student and educator learning norms collide}

The current paper is an exploration of the consequences that social identification and perceived normative conflict have for learning approaches among tertiary students. Specifically, it aims to unpack the potential influences of multiple ingroup norm communications, in cases of both congruence and inconsistency. Social psychological literature (e.g. Turner, 1991) has established that the combination of the extent to which an individual identifies with a particular group membership (i.e. perceives it as self-defining) and the nature of the norms they perceive to belong to that group have a demonstrable effect on specific, norm-related behaviour (e.g. healthy eating, Baker, Little, \& Brownell, 2003; exercise, Hagger \& Chatzisarantis, 2005). The current paper examines an under-studied aspect of this process (McDonald, Fielding, \& Louis, 2013, 2014), in that these norms may not be monolithic, nor derived from a single intragroup source. Building on previous work on the social psychological processes of education, the immediate, task-bound context of the current investigation is higher education.

The utility of considering field of study related identification and perceived learning norms in predicting student learning behaviour and academic success has already been demonstrated (Bliuc, Ellis, Goodyear, \& Hendres, 2011a, 2011b; Platow, Mavor, \& Grace, 2013; Smyth, Mavor, \& Platow, 2017; Smyth, Mavor, Platow, Grace, \& Reynolds, 2015) . In this literature, and the current paper, learning behaviour is couched chiefly in terms of learning approaches; a descriptive typology drawn from the education literature (John Biggs, 1999; John Biggs \& Tang, 2007a). In this model, learning behaviours and strategies are divided into those that seek to integrate information for the sake of understanding (deep learning) and those that seek to memorise information for the sake of task completion (surface learning). These approaches have already been demonstrated to be subject to 
influence from strength of identification with a relevant social identity and from perceived study-related norms associated with these identities (Bliuc et al., 2011a, 2011b; Platow et al., 2013; Smyth et al., 2015). The current paper takes this body of research a step further, in line with the direction suggested more recently by Smyth and colleagues (Smyth, Mavor, Platow, \& Grace, 2017), by examining learning approach intentions in a situation where multiple, potentially conflicting, intragroup normative influences are considered, particularly those drawn from the educator.

\section{Learning approaches and education}

In order to understand how these conflicts might play out, it is necessary to be clear on the existing explanatory frameworks for learning behaviour decisions. The learning approaches model, proposed by Marton and Säljö (1976), and developed by Biggs (1979, 1999), suggests that students engage with the task or material they are given in one of two broad manners: (1) deep learning: engaging and seeking to understand intent and broader implications, or (2) surface learning: focusing on completion of task requirements and often resorting to memorisation. A key aspect of the model is that learning "approach" is understood as not something a student has, but rather something a student takes in a particular situation, to a particular task: it is assumed to be context-dependent (John Biggs, 1999).

\section{The role for social identification}

Building on these models from a social identity perspective (Tajfel \& Turner, 1986; Turner, Hogg, Oakes, Reicher, \& Wetherell, 1987), researchers have argued in favour of considering social identities as important factors that contribute to the nature of student learning approaches (Bliuc et al., 2011a, 2011b; Platow et al., 2013). The social identity approach conceptualizes the individual's sense of self as flexible, context dependent, and comprised partly of social identities. These identities arise from seeing oneself as a member 
of a social group, the associated sense of belonging, and the cognitive significance attached to the memberships. The more self-defining these identities are, the stronger an effect they have on cognition, behaviour, and emotion.

In applying this understanding of the self to a learning context, Bliuc et al. (2011a, 2011b) proposed a model (which is supported by their findings) that suggests students who identify more strongly with their field of study would be more likely to adopt a deep learning approach and, therefore, have better academic outcomes. Platow and colleagues (2013) similarly test a model in which the field of study-related social identity and learning approach and are reciprocally influential over time, and find that deeper learning approaches at Time 1 predicted increased identification levels.

Smyth and colleagues (Smyth, Mavor, \& Platow, 2017; Smyth et al., 2015) build on these findings through the addition of a normative dimension. These authors find again that social identification is a significant positive predictor of the extent to which students adopt a deep learning approach, but also that this effect is moderated by the perceived norms for the group. That is, it is not only the strength of identification with a group that influences learning approach behaviour, but also what that group membership means, in terms of norms for group behaviour.

\section{Normative conflict}

The novel contribution of the current paper, then, is an examination of behavioural outcomes where the learning approach norm for the study-related social identity is unclear, contested or in conflict. This idea of heterogeneous ingroup normative position is not new in the literature. The meaning of social identities and groups memberships are not conceptualised as static, and it is rare in groups that there is only one prescribed notion of what the group is and how they should behave (Reicher, 2004; Reicher \& Hopkins, 1996). Normative conflict, then, can take a range of forms. Norms can change on the basis of 
adopting different roles (Biddle, 1986); norms of competing groups and changes in group composition over time (e.g. Sherif \& Sherif, 1967); and conflict between perceptions of general group members and deviants who effectively redefine the group (e.g. Chan, Louis, \& Hornsey, 2009; Warren, 2003). Individuals in the group, and subgroups from within the larger group, often have differing notions regarding the group's identity, which manifest in their behaviour (Hornsey, 2006; Postmes, Baray, Haslam, Morton, \& Swaab, 2006). As such, it is not a stretch to imagine that a group member may be exposed to multiple competing standards for behaviour from within their group (Packer, 2008).

One way of seeing these various examples of norm conflict is as varying on a continuum from situations of conflicting identities (with associated norms) to conflict over multiple plausible norms of a single identity at the other. At one end of this specturm, work by McDonald and colleagues (McDonald et al., 2013, 2014) examined conflict where several alternative ingroups (e.g., family vs. friends) offer potentially conflicting norms on a common behaviour. These authors found that conflicting norms expedited behavioural decisionmaking, in that people were motivated to take action to resolve the cognitive dissonance that arose from the conflict. This clear choice of separate group label has the net effect of the conflict being resolved when the participant chooses which identity's norms to align themselves with. In the current paper, we work at the other end of this norm conflict spectrum. We attempt to examine these conflict processes where the participant is not given the option to not resolve the substantive normative conflict (by choosing identities) and must, instead, integrate or resolve the two normative messages.

\section{Normative conflict in education}

We argue that this clash of normative messages from different intragroup sources arises relatively frequently in higher education contexts (Killen, 1994). For example, it is easy to imagine a class in which the educator communicates to the students that the best 
approach to the course is one wherein the learner integrates new and existing information and makes good use of available learning resources. However, the student is also exposed to the behaviour and values of fellow students, and may well find themselves also encouraged toward a more surface-learning-oriented approach.

A key aspect of the above-described situation is that both the educator and the fellow students can be understood as members of a psychologically meaningful social identity (which can be broadly considered the field-of-study). We would expect, from the existing literature (McNeill, Smyth, \& Mavor, 2017; Smyth, Mavor, Platow, et al., 2017; Smyth et al., 2015), that this field-of-study identification and associated peer-derived norms will have impact on student learning approaches. However, on the basis that the educator has both structural power (as the awarder of grades) and social-identity-based power (as a successful field-of-study group member; Ellemers, De Gilder, \& Haslam, 2004), we would also anticipate that educator-derived norms would be both meaningful and impactful.

The idea of the educator attempting to influence student perceptions of the "right" way to study in the field is, obviously, not new. Much of the education literature provides evidence that structural factors including workload and assessment influence student learning (e.g. Baeten, Kyndt, Struyven, \& Dochy, 2010; Barrie, 2006; John Biggs \& Tang, 2007a; Gibbs, 1999; Kember, 2004; Lizzio, Wilson, \& Simons, 2002; Newble \& Jaeger, 1983). An alignment between learning activities and assessment ("constructive alignment" John Biggs \& Tang, 2007b) has been linked to shaping student learning approaches and improving student academic performance (e.g. John Biggs \& Tang, 2007b; Wang, Su, Cheung, Wong, \& Kwong, 2013). What we are arguing for here is a reconceptualization of this alignment and course structuring as group norm communications. That is, in setting learning outcomes and deciding on learning activities and course structure, the educator is implicitly communicating field-of-study-specific norms. 
To elucidate how this might be a normative effect, it is useful to consider an example. For instance, in deciding how large a workload to give to students, the educator is implicitly communicating the amount of time a student should spend on each task, and the expected depth of analysis. If the student behaves in accordance with these norms, and the course is constructively aligned, the student should achieve a good grade- and their adherence to the implicit norm is reinforced with a reward.

Working from this notion that normative communications from both peers and educators are consistently present within the broader "field of study" group, we must then ask, how students manage these multiple sets of ingroup normative messages and how this impacts on learning. When these two sets of norms are concordant, we would expect (and literature has demonstrated) amplification of the effect of norms on behaviour (McDonald et al., 2013, 2014). The crux of the current research question is how competing normative influences might be resolved and in what way these processes are moderated by strength of identification with the field.

\section{The Present Study}

From the perspective of a tertiary student, there are at least two meaningful sources of learning approach norms. The current research aims to identify the patterns of influence of these sources on student learning in an undergraduate student sample.

\section{Expectations}

We have several expectations for the data. First, we expect to find, in line with previous literature in this area (Bliuc et al., 2011a, 2011b; Platow et al., 2013; Smyth et al., 2015), that stronger identification with the field of study group will lead to the adoption of deeper learning approaches, and that this effect will be moderated by perceived student norms (H1). However, we also expect a moderating role for perceived educator norms (H2). Our 
Social Identification and Normative Conflict: 10

expectations with regard to how these sets of norms are resolved in instances of conflict are largely exploratory, but some form of three-way interaction between identification, student norm and educator norm is possible (H3). Our expected model is in Figure 1.

[Insert Figure 1 near here] 
Social Identification and Normative Conflict: 11

\section{Method}

\section{Design}

The current study was a between-subjects design, wherein participants were exposed to one of three educator-norm conditions and reported on their existing perceptions of student norms in their field before completing a learning approach measure and completing a learning task. While we focus here on only two normative influences which are part of a potentially more complex situation, we consider this appropriate. In our view, influences from broader meta-stereotypes would be largely mediated through the student perceptions of these key educational relationships, as students assimilated their pre-existing or external expectations with their real-classroom experiences. We note, however, that this may change as trends in university delivery move away from face-to-face lecture sessions and there may be a future need to consider the influence of field-of-study meta-stereotypes more centrally.

\section{Participants}

The final sample consisted of 229 participants (67\% female; $75 \%$ reported as English as their first language) recruited via posters and online, across eight Australian institutions and 41 different fields of study. As a result of the complex design and the novel nature of the effects of interest we determined 200 to be the smallest usable sample size and collected data until there were more than this number of fully complete study responses (Simmons, Nelson, \& Simonsohn, 2011; e.g. Wilson Van Voorhis \& Morgan, 2007)). Participants ranged from 17 to 46 years of age $(M=20.72, \mathrm{SD}=3.18)$.

\section{Procedure}

This study was conducted online. Upon commencing, participants were presented with a page describing a cover story for the experiment- that the university was introducing a 
new critical reading course and the purpose of the study was to road test the course outline and first assessment task for this course.

Participants were first asked to indicate their degree program and main field of study, to make identification with their field of study group salient. Educator norms were then manipulated, using invented 'Course Outline' documents designed to communicate particular educational norms. This was followed by a range of measures designed to capture: field of study-related social identification, learning approaches, and perceived student learning norms. This was followed by a comprehension task designed to measure actual learning behaviour $^{1}$ and, finally, some participant demographics.

\section{Measures}

\section{Manipulation of educator-driven norms.}

Perceived educator norms were manipulated using mock course-outlines for a "Critical Reading" course in the current study. This course was deliberately broad, to allow relevance to a wide range of disciplines, and was modelled on some existing interdisciplinary courses at the authors' institution which are not bound to a specific field of study. Three outlines were developed modelled on the same template. One outline was designed to reflect an educator norm of 'deep' learning, one a 'surface' norm and one was a 'neutral' mix of both. Each participant was only exposed to one type of course outline.

The three conditions were created by systematically varying attributes of the course. The attributes chosen were derived from the literature on available methods for course design to promote deep learning (Thomas \& Bain, 1982; Trigwell \& Prosser, 1991). These variables included: workload (i.e. the number and scope of assessment pieces, (Lawless \& Richardson, 2002; Wilson, Lizzio, \& Ramsden, 1997), timing of assessment (Tan, 1992) and the nature of assessment items (Moon, 1999; Scouller, 1998) ${ }^{2}$. 
Participants were shown one of these course outlines and asked to imagine that they were taking the course to which the outline refers. They were asked to read the outline carefully and think about how they would study in this course. Participants were then asked a five basic multiple-choice comprehension items (e.g. "how many assignments are in this course"; "what are this course convenor's learning priorities"), to ensure they had read the outline and as a manipulation check to ensure they had perceived the outlines as intended. All participants completed these in the manner we would expect. Participant responses reflected that these outlines were convincing, participants were actually reading them and the outlines were communicating the norms intended.

It is important to note here that this operationalisation means that, of the two sets of conflicting norms, one set are measured (student norms) and the other are manipulated (educator norms). While this has impact on the inferences we can draw, we also argue that this has ecologically validity; student norms are likely derived from a range of sources, across a range of situations, whereas course-bound educator norm communications are far more standardised, concrete and issued from a limited number of sources. As such, having rigidly standardised educator norm communications, and a measure of student norms that is open to participant construal would, in our view, capture the processes in real learning contexts.

\section{Follow-up measures}

Participants were then presented with a series of statements and indicated their degree of agreement or disagreement with the scale items on a five-point Likert scale (ranging from strongly disagree to strongly agree), unless specified otherwise. In example items below an (r) indicates a reversed item.

\section{Field of study-related social identification.}

Identification as a student in their field of study was measured using a scale of seven items that are widely used to measure social identification (see Haslam, 2004). In order to 
anchor participant perceptions at the more-inclusive "field of study" level (rather than defaulting to the competing sub-identities of students-in-my-field or educators-in-my-field), the wording of items was in terms of "my field of study". This scale has been previously used to measure social identification levels with field of study-related social identity (Bliuc et al., 2011a, 2011b; Platow et al., 2013; Smyth et al., 2015). Items included: "Being in my field of study is important to me" and "I would RATHER NOT tell other people that I am a student in my field of study" (r)". In the current data, the scale was acceptably reliable $(\alpha=.78)$.

\section{Learning Approaches and Perceived Norms}

Students' learning approaches were measured using 12 items adapted from the revised version of the Study Process Questionnaire (SPQ; J. Biggs, Kember, \& Leung, 2001) with regard to the imagined course. Six items measured each learning approach (e.g., "I spend a lot of my free time finding out more about interesting topics dealt with in class" (deep); "I only study seriously those topics that I know will be assessed" (surface). In the current data, the alpha values $\left(\alpha_{\text {deep }}=.68 ; \alpha_{\text {surface }}=.66\right)$ fell slightly below the conventional cut-off of 0.70 (Tavakol \& Dennick, 2011), however, given the smaller number of items and the established reliability of this commonly-used scale for this kind of context (Bliuc et al., 2011a, 2011b; Platow et al., 2013; Smyth et al., 2015), the scale was treated as acceptable.

Six items were used to assess perceptions of norms among students in their field of study adapted from the SPQ (three for each kind of norm; e.g., "Most students in my field of study prefer to focus on learning efficiently by memorizing key information and minimizing study time" (surface); "Most students in my field of study prefer to focus on understanding content fully and integrating new information with what they already know" (deep). These items are designed to reflect the approaches captured by the SPQ, but are worded positively and have been previously used in tertiary populations (Smyth et al., 2015). These six items were then used to construct a single "valence of student norm" measure. Surface learning 
norms were reverse coded and all six items were averaged, yielding a single score where positive scores indicate a net tendency toward deep learning norms and negative scores indicate a net tendency toward surface learning. While we acknowledge that deep and surface learning are, conceptually, independent constructs and not the anchor points of a continuum (John Biggs, 1987), the specific behaviours we have used as targets for our normative items are, in essence, fundamentally incompatible. This leaves the student with what amounts to a binary choice and we therefore consider this approach to calculating the norm "valence" appropriate. In the current data, the learning norm valence scale (i.e. All six norms items, with surface norms reverse coded) fell above the recommended reliability level $\left(\alpha_{\text {stnorm }}=.75\right)$.

\section{Demographics \& perceptions of the educator}

Demographic questions regarding participant gender, age and whether they were from a non-English speaking background (NESB) were asked at the end of the online survey. In the interests of controlling for any leadership-associated effects, participants were also asked how prototypical of their field of study they perceived the course convenor to be, using the Identity leadership inventory (Steffens et al., 2014). This inventory included items such as: 'This course convenor exemplifies what it means to be a member of this field of study group'. In the current data, this scale was acceptably reliable $(\alpha=.88)$. However, it was not significant related to the other variables of interest and so was not considered further. At the end of the study, participants were debriefed on the true purpose of the research. 


\section{Results}

Data were analysed in two steps. First, means and correlations of key variables were examined to see if the patterns were broadly consistent with previous research. Second, a moderated multiple regression model was tested, exploring the main effects of identification and each type of norm, and their interactions. Multiple regression was chosen over SEM owing to the nature of our research questions. Our hypotheses amount to a directional interaction model, examining effects of educator social influence, over and above the alreadyestablished student social influence. For this reason, we examined our data using sequential moderated multiple regression (Aiken \& West, 1996; Tabachnick \& Fidell, 2001).

\section{Preliminary Analysis}

Table 1 presents the means, standard deviations, and correlations between all variables. There are few significant relationships between any of the demographics (age, gender, and language background) and our key variables and those that are present, are small in size. This is also the case with regard to relationships with the leadership variable. To simplify analyses and focus the model on our key variables of interest, the demographic variables and leadership measure ${ }^{3}$ were not included in further analysis.

There are several important things to note about the correlational associations. First, stronger identification with the field of study is related to deeper learning approaches $(r=.39$, $p<.01$ ) and deeper learning norms (as indicated by a significant positive relationship with our norm valence construct, $r=.21, p<.01$ ), as we would expect from the previous literature. Second, self-reported deeper learning approaches also demonstrate the expected pattern of relationships. Deeper learning approaches were positively associated with deep learning norms $(r=.39, p<.01)$ and negatively associated with surface learning approaches $(r=-.46$ $p<.01)$ 


\section{Model testing}

To test the hypotheses that student learning approaches will be subject to influence by identification level, and both sets of perceived norms, and more specifically, whether (and how) both types of norms have influence on the identification-learning approach relationship, two hierarchical multiple regression analyses were conducted (one predicting each type of learning approach). Following common practice, the variables were centred, and interaction product terms between each type of norm (student and educator) and level of identification were created (Aiken \& West, 1991).

\section{Deep learning approaches}

In the first step, the main effect variables were included: identification, student norm valence and educator norms. These accounted for a significant amount of variance in student deep learning approaches, $\left.R^{2}=.24, F(4,192)=14.96, p<.001\right)$ and indicated significant positive main effects for identification $(\beta=.28, p<.01)$ and student norm valence $(\beta=.33$, $p<.01)$. Next, the two-way interaction terms between student norms, identification, and educator norms were added to the regression model, which accounted for a significant increase in the variance in learning approaches, $\left.\Delta R^{2}=.06, F(5,187)=3.01, p<.05\right)$ and indicated a significant two-way interaction between student norm and identification level $(\beta=$ $.21, p<.01)$. Regression coefficients for each interaction term can be seen in Table 2 . In the third step, three-way interactions between identification, student norm valence and educator norms were entered $\left(\Delta R^{2}=.03, F(2,185)=3.88, p<.05\right)$. This final block indicated that the significant two-way interaction in step two was only significant in the control condition and was non-significant in the other two conditions (see Table 2 for coefficients).

Examination of the interaction plot (see Figure 2a) showed that, in the control condition (with no clear educator norms), we find the moderation effect reported by Smyth et al (2015). For students not strongly identified, the strength of the perceived student norms has 
no significant effect on learning approaches $(\beta=-.01, n s)$. For strongly identified students, however, increasing strength of deep learning norms was associated with increasing strength of deep learning approaches $(\beta=.34, p<.05)$. In the deep and surface educator norms conditions, however, this two way interaction is not present, and we only see the main effects. In the "deep" conditions, both identification and student norm valence were positive main effect predictors $(\beta=.30, p<.01$ and $\beta=.34, p<.01$, respectively) of deep learning approach. In the surface educator norm condition, however, only student norm valence was a predictor of deep learning approach $(\beta=.41, p<.01)$. There was no effect for identification.

\section{Surface learning approaches}

In the first step, the main effect variables were included: identification, student norm valence and educator norms. These accounted for a significant amount of variance in student deep learning approaches, $\left.R^{2}=.18, F(4,192)=10.84, p<.05\right)$. A significant, negative main effect was found for norm valence, predicting surface learning $(\beta=-.38, p<.01)$. Next, the two-way interaction terms between norms and identification were added to the regression model, which did not account for a significant proportion of the variance in learning approaches, $\left.\Delta R^{2}=.04, F(5,187)=1.79, n s\right)$. Regression coefficients for each interaction term can be seen in Table 2. In the third step, three-way interactions between identification, student norm valence and condition (educator norms) were entered $\left(\Delta R^{2}=.01, F(2,185)=\right.$ 1.16, $n s)$. This final block was also non-significant, indicating no three-way interactions between identification, student norm and educator norm on surface learning approach, in this sample (see Table 3). 


\section{Discussion}

The current paper sought to examine in further detail the social influence processes already demonstrated to occur in tertiary learning (Bliuc et al., 2011a, 2011b; Platow et al., 2013; Smyth et al., 2015). Specifically, it sought to demonstrate the possible effects of ambiguous or conflicting information on norms for learning behaviour associated with the field-of-study identity. We argue that, in realistic learning contexts, normative territory can be contested and different in-group sources (e.g. fellow students vs. course instructor) can communicate differing norms to students. The core aim of the current study was to examine the outcomes of these potentially conflicting norms and the moderating role for identification.

Results from the correlation and regression analyses are all in line with previous literature (Bliuc et al., 2011a, 2011b; Platow et al., 2013; Smyth, Mavor, \& Platow, 2017; Smyth et al., 2015). As in these previous studies, there is a positive main effect association here between identification and the adoption of deeper learning approaches. We also find that a stronger perceived norm in favour of a particular learning approach was associated with a greater tendencies toward reporting that learning approach.

Where this study makes a novel contribution is in the inclusion of educator norms. These were manipulated in our paradigm, so as to ensure they were somewhat standardised across a heterogeneous student sample from a range of fields of study. We tentatively expected some form of three-way interaction between identification, student norms, and educator norm condition. We hypothesized that this interaction would be such that instances where student and educator norms match should amplify the normative effects and in instances where there was conflict, results would indicate how students integrate heterogeneous normative messages to form an impression of identity-related study expectations. We found a single three-way interaction of this type, predicting deep learning. The form of the interaction was such that the previously established identification by norm 
interaction was found only in the control condition (where educator norms are unclear), see Figures $2 \mathrm{a}, \mathrm{b} \& \mathrm{c}$. This three-way interaction was not present in predicting surface learning approaches.

[Insert Figures 2a, 2b \& 2c near here]

This interaction presents us with an interesting patterning of normative influence. The immediate question is why the student norms by identification interaction that has been produced in the literature (McNeill et al., 2017; Smyth, Mavor, \& Platow, 2017; Smyth, Mavor, Platow, et al., 2017; Smyth et al., 2015) is only present in the case of absent or ambiguous educator norms. It is first important to note that, due to the way these studies have previously been conducted, this finding is entirely consistent with previous findings. Previous explorations of this interaction have not included educator norms in the model and have sampled a mixed population of students across fields of study, institutions and degree programs. As such, the educator normative messages in these previous studies was likely relatively heterogeneous or ambiguous, much like our current "control” condition.

The more useful part of this three-way interaction is the evidence from the other two conditions: that clear, directional educator norms can alter the established influence of student norms. When educator and student norms align in these conditions, the learning approaches of strong-identifiers reflect this clear, uniform message. Clear educator norms that are congruent with student norms bolster the strength of the effect of student norms.

The pattern of results in the conflict conditions is slightly more complex. The fulcrum of this pattern of results is the long-reported associated between stronger identification and deeper learning approaches (e.g. Bliuc et al., 2011b). In essence, when the two sets of norms are in conflict, we get only the identification main effect: strong identifiers report deeper learning approaches. This may indicate that, when normative messages are incongruent, students disengage from normative influences, leaving only the identification main effects. 
This would be in keeping with the demotivating effects discussed in McDonald and colleagues (McDonald et al., 2013), where conflicting norms alter perceptions of collective action efficacy, attenuating the impact of perceived norms on behavioural decisions. This finding also meshes well with the above-mentioned original finding in the literature that strong identifiers tend toward deep learning approaches and may reflect that, in fact, there is some kind of meta-stereotype of a "good student" that students are quick to default to, in the event of normative support from any intragroup quarter (student or educator).

To summarise the implications of this interaction for deep learning, we find that:

1. Educator norms that align with student norms can bolster the impact of norms on learning approaches, either toward or away from deep learning;

2. Ambiguous, absent or heterogeneous educator norms produce the student normby-identification interaction for deep learning as previously reported in the literature; and,

3. When educator norms contradict student norms, students appear to disengage from normative influences and default to the simple identification-deep learning association frequently identified in the literature (possibly reflecting some larger meta-identity or stereotype of what it means to be a "good" student).

One consideration needs to be borne in mind in interpreting the real-world implications of this pattern of findings is the indirect nature of the educator norm manipulation in the current study, as compared to the proximal, direct perceived influence of the participant's fellow students. While we acknowledge this potential mismatch, we would argue that this operationalisation was, in some respects, veridical (as discussed in the method section). However, in interpreting findings it is important to consider possible consequences of this design decision. With regard to the three-way interaction, the net effect of the norm operationalisations may be that, while the educator norms are strong enough to create 
confusion or conflict with existing student-driven effects, they are not necessarily strong or clear enough to instigate a new pattern of norms. What may be missing from these manipulation is the interaction aspect of this relationship. In a real-world setting, educators would also (implicitly or explicitly) communicate learning approach norms more directly in their direct interactions with the students. As such, the possible influence of educator norms in this context may be understated in the current data. Future research might manipulate the strength of conflicting norms to examine the strength of educator norm required to undo influence from undesirable student norms.

A second note on applying these findings to real-world education context is that, as mentioned earlier, we have limited our investigation to two, clear intragroup norm sources. In an educational setting, however, we may also wish to consider the broader meta-stereotypes of the field of study. Smyth and colleagues'(Smyth, Mavor, \& Platow, 2017) findings, for example, suggest potential meaningful variation in the learning norms and approaches by field of study. In the current study this is partially addressed by testing models that include the students' fields of study. However, we largely limit our analysis to the two, clear intragroup norm sources that are most proximal to the student experience (educator and peers). There is clear scope to either measure or manipulate the field-level normative information and consider how this information may further complicate the norm-deriving process for students.

In summary, these findings provide support for the notion that field of study related social identity (Bliuc et al., 2011a, 2011b; Platow et al., 2013) and perceived student norms embedded in the learning environment (Smyth, Mavor, \& Platow, 2017; Smyth et al., 2015) play a substantive role in determining student learning approaches. However, findings also suggest that it is not only peers that have a normative influence on learning, but also the educator. In our data, students have demonstrably used normative information from multiple 
ingroup sources to derive their understanding of group norms. In turn, these understandings of group norms have impact on the learning approaches associated with the field-of-study related identity.

From a practical standpoint, there are several possible lessons to be drawn from this work. First, norm conflict can arise in a number of ways and that it can be useful to model norm conflict in education settings as a set of competing norms associated with a shared field-of-study identity. As such, in trying to predict or manage student learning behaviour, it is important to consider the complex and varied normative messages being communicated to students from various sources associated with their field of study. Second, our findings would indicate that, in cases where the educator does not take a clear normative position, students may default to deriving their understanding of learning norms from their peers. Depending on the peer group in question, this can be either to the detriment or advantage of their learning and long-term outcomes. Finally, findings would indicate that there is scope for an educator to shape student perceptions of norms. Previous literature has made clear that student identification and perceptions of norms have influence on behaviour (Smyth et al., 2015). Our findings indicate that this is a process that the educator can attempt to manage, through their own normative communications. Future research should address ways in which this can be done and what the effective strength threshold might be, with regard to managing potential conflict with student normative messages. 
Social Identification and Normative Conflict: 24

\section{References}

Baeten, M., Kyndt, E., Struyven, K., \& Dochy, F. (2010). Using student-centred learning environments to stimulate deep approaches to learning: Factors encouraging or discouraging their effectiveness. Educational Research Review, 5(3), 243-260. doi: 10.1016/j.edurev.2010.06.001

Baker, C. W., Little, T. D., \& Brownell, K. D. (2003). Predicting adolescent eating and activity behaviors: the role of social norms and personal agency. Health Psychol, 22(2), 189-198. doi: http://dx.doi.org/10.1037/0278-6133.22.2.189

Barrie, S. (2006). Understanding what we mean by the generic attributes of graduates. Higher Education, 51(2), 215-241. doi: 10.1007/s10734-004-6384-7

Biddle, B. J. (1986). Recent Developments in Role-Theory. Annual review of sociology, 12(1), 67-92. doi: DOI 10.1146/annurev.so.12.080186.000435

Biggs, J. (1979). Individual-Differences in Study Processes and the Quality of Learning Outcomes. Higher Education, 8(4), 381-394. doi: Doi 10.1007/Bf01680526

Biggs, J. (1987). Student Approaches to Learning and Studying. Research Monograph: ERIC.

Biggs, J. (1999). What the student does: teaching for enhanced learning. Higher Education Research \& Development, 18(1), 57-75. doi: http://dx.doi.org/10.1080/0729436990180105

Biggs, J., Kember, D., \& Leung, D. Y. (2001). The revised two-factor Study Process Questionnaire: R-SPQ-2F. Br J Educ Psychol, 71(Pt 1), 133-149. doi: $10.1348 / 000709901158433$ 
Social Identification and Normative Conflict: 25

Biggs, J., \& Tang, C. (2007a). Teaching according to how students learn. Teaching for Quality Learning at University (3 ed., pp. 15-30). Maidenhead: Open University Press.

Biggs, J., \& Tang, C. (2007b). Using constructive alignment in outcomes-based teaching and learning. Teaching for Quality Learning at University (3 ed., pp. 50-63). Maidenhead: Open University Press.

Bliuc, A. M., Ellis, R. A., Goodyear, P., \& Hendres, D. M. (2011a). The role of social identification as university student in learning: relationships between students' social identity, approaches to learning, and academic achievement. Educational Psychology, 31(5), 559-574. doi: 10.1080/01443410.2011.585948

Bliuc, A. M., Ellis, R. A., Goodyear, P., \& Hendres, D. M. (2011b). Understanding student learning in context: relationships between university students' social identity, approaches to learning, and academic performance. European Journal of Psychology of Education, 26(3), 417-433. doi: 10.1007/s10212-011-0065-6

Chan, M. K., Louis, W. R., \& Hornsey, M. J. (2009). The effects of exclusion and reintegration on the evaluation of deviant opinion holders. Pers Soc Psychol Bull, 35(12), 1619-1631. doi: 10.1177/0146167209346972

Ellemers, N., De Gilder, D., \& Haslam, S. A. (2004). Motivating individuals and groups at work: A social identity perspective on leadership and group performance. Academy of Management Review, 29(3), 459-478. doi:

http://dx.doi.org/10.5465/amr.2004.13670967

Gibbs, G. (1999). Using Assessment Strategically to Change the Way Students. In J. Jr. Brown (Ed.), Assessment matters in higher education (pp. 41): McGraw-Hill Education 
Social Identification and Normative Conflict: 26

Hagger, M. S., \& Chatzisarantis, N. L. (2005). First- and higher-order models of attitudes, normative influence, and perceived behavioural control in the theory of planned behaviour. Br J Soc Psychol, 44(Pt 4), 513-535. doi: 10.1348/014466604X16219

Haslam, S. A. (2004). Psychology in organizations: The social identity approach (2nd ed.). London: Sage.

Hornsey, M. J. (2006). Ingroup critics and thier influence on groups. In T. Postmes \& J. Jetten (Eds.), Individuality and the group: Advances in soical identity (pp. 74-91). Thousand Oaks, CA: Sage.

Kember, D. (2004). Interpreting student workload and the factors which shape students' perceptions of their workload. Studies in Higher Education, 29(2), 165-184. doi: http://dx.doi.org/10.1080/0307507042000190778

Killen, R. (1994). Differences between Students' and Lecturers' Perceptions of Factors Influencing Students' Academic Success at University. Higher Education Research \& Development, 13(2), 199-211. doi: 10.1080/0729436940130210

Lawless, C. J., \& Richardson, J. T. (2002). Approaches to studying and perceptions of academic quality in distance education. Higher Education, 44(2), 257-282. doi: Doi 10.1023/A:1016315114558

Lizzio, A., Wilson, K., \& Simons, R. (2002). University students' perceptions of the learning environment and academic outcomes: Implications for theory and practice. Studies in Higher Education, 27(1), 27-49. doi: http://dx.doi.org/10.1080/03075070120099359

Marton, F., \& Säljö, R. (1976). On qualitative differences in learning — 1: Outcome and process. British Journal of Educational Psychology, 46, 4-11. doi: http://dx.doi.org/10.1111/j.2044-8279.1976.tb02980.x 
McDonald, R. I., Fielding, K. S., \& Louis, W. R. (2013). Energizing and de-motivating effects of norm-conflict. Pers Soc Psychol Bull, 39(1), 57-72. doi: $10.1177 / 0146167212464234$

McDonald, R. I., Fielding, K. S., \& Louis, W. R. (2014). Conflicting Norms Highlight the Need for Action. Environment and behavior, 46(2), 139-162. doi: $10.1177 / 0013916512453992$

McNeill, K. G., Smyth, L., \& Mavor, K. I. (2017). The complexity of medical education: Social identity and normative influence in well-being and approaches to learning. In K. I. Mavor, M. J. Platow \& B. Bizumic (Eds.), Self and Social Identity in Educational Contexts. Abingdon: Routledge.

Moon, J. (1999). Reflection in learning and professional development. Abingdon, Oxon: RoutledgeFalmer. doi: http://dx.doi.org/10.4324/9780203822296

Newble, D. I., \& Jaeger, K. (1983). The effect of assessments and examinations on the learning of medical students. Medical Education, 17(3), 165-171. doi: http://dx.doi.org/10.1111/j.1365-2923.1983.tb00657.x

Packer, D. J. (2008). On being both with us and against us: a normative conflict model of dissent in social groups. Pers Soc Psychol Rev, 12(1), 50-72. doi: $10.1177 / 1088868307309606$

Platow, M. J., Mavor, K. I., \& Grace, D. M. (2013). On the role of discipline-related selfconcept in deep and surface approaches to learning among university students. Instructional Science, 41(2), 271-285. doi: 10.1007/s11251-012-9227-4

Postmes, T., Baray, G., Haslam, S. A., Morton, T. A., \& Swaab, R. (2006). The dynamics of personal and social identity formation. In T. Postmes \& J. Jetten (Eds.), Individuality and the Group: Advances in social identity (pp. 215-237). London: SAGE Publications. 
Social Identification and Normative Conflict: 28

Reicher, S. (2004). The context of social identity: Domination, resistance, and change. Political Psychology, 25(6), 921-945. doi: DOI 10.1111/j.1467-9221.2004.00403.x

Reicher, S., \& Hopkins, N. (1996). Self-category constructions in political rhetoric; an analysis of Thatcher's and Kinnock's speeches concerning the British miners' strike (1984-5). European Journal of Social Psychology, 26(3), 353-371. doi:

http://dx.doi.org/10.1002/(sici)1099-0992(199605)26:3\%3C353::aidejsp757\%3E3.0.co;2-o

Scouller, K. (1998). The influence of assessment method on students' learning approaches: Multiple choice question examination versus assignment essay. Higher Education, 35(4), 453-472. doi: Doi 10.1023/A:1003196224280

Sherif, M., \& Sherif, C. W. (1967). Conformity-deviation, norms, and group relations. In M. Sherif (Ed.), Social Interaction (pp. 164-189). Chicago: Aldine.

Simmons, J. P., Nelson, L. D., \& Simonsohn, U. (2011). False-Positive Psychology: Undisclosed Flexibility in Data Collection and Analysis Allows Presenting Anything as Significant. Psychological Science, 22(11), 1359-1366. doi:

$10.1177 / 0956797611417632$

Smyth, L., Mavor, K. I., \& Platow, M. J. (2017). Learning behaviour and learning outcomes: the roles for social influence and field of study. Social Psychology of Education, 20(1), 69-95. doi: 10.1007/s11218-016-9365-7

Smyth, L., Mavor, K. I., Platow, M. J., \& Grace, D. M. (2017). Understanding social identity in education: The modifying role for perceived norms. In K. I. Mavor, M. J. Platow \& B. Bizumic (Eds.), Self and Social Identity in Educational Contexts. Abingdon: Routledge. 
Social Identification and Normative Conflict: 29

Smyth, L., Mavor, K. I., Platow, M. J., Grace, D. M., \& Reynolds, K. J. (2015). Discipline social identification, study norms and learning approach in university students. Educational Psychology, 35(1), 53-72. doi: 10.1080/01443410.2013.822962

Steffens, N. K., Haslam, S. A., Reicher, S. D., Platow, M. J., Fransen, K., Yang, J., . . Boen, F. (2014). Leadership as social identity management: Introducing the Identity Leadership Inventory (ILI) to assess and validate a four-dimensional model. Leadership Quarterly, 25(5), 1001-1024. doi: 10.1016/j.leaqua.2014.05.002

Tajfel, H., \& Turner, J. C. (1986). The social identity theory of intergroup behaviour. In S. Worshel, and Austin, W. (Ed.), Psychology of intergroup relations. Chicago: Nelson Hall.

Tan, C. M. (1992). An Evaluation of the Use of Continuous Assessment in the Teaching of Physiology. Higher Education, 23(3), 255-272. doi: Doi 10.1007/Bf00145016

Tavakol, M., \& Dennick, R. (2011). Making sense of Cronbach's alpha. Int J Med Educ, 2, 53-55. doi: 10.5116/ijme.4dfb.8dfd

Thomas, P. R., \& Bain, J. D. (1982). Consistency in learning strategies. Higher Education, 11(3), 249-259. doi: Doi 10.1007/Bf00155616

Trigwell, K., \& Prosser, M. (1991). Improving the quality of student learning: the influence of learning context and student approaches to learning on learning outcomes. Higher Education, 22(3), 251-266. doi: Doi 10.1007/Bf00132290

Turner, J. C. (1991). Social Influence. Milton Keynes: Open University Press.

Turner, J. C., Hogg, M., Oakes, P., Reicher, S., \& Wetherell, M. (1987). Rediscovering the social group: A self-categorization theory. Oxford: Blackwell.

Wang, X. Y., Su, Y. L., Cheung, S., Wong, E., \& Kwong, T. (2013). An exploration of Biggs' constructive alignment in course design and its impact on students' learning 
Social Identification and Normative Conflict: 30 approaches. Assessment \& Evaluation in Higher Education, 38(4), 477-491. doi: $10.1080 / 02602938.2012 .658018$

Warren, D. E. (2003). Constructive and Destructive Deviance in Organizations. Academy of Management Review, 28(4), 622-632. doi: 10.5465/amr.2003.10899440

Wilson, K. L., Lizzio, A., \& Ramsden, P. (1997). The development, validation and application of the Course Experience Questionnaire. Studies in Higher Education, 22(1), 33-53. doi: 10.1080/03075079712331381121

Wilson Van Voorhis, C. R., \& Morgan, B. L. (2007). Understanding Power and Rules of Thumb for Determining Sample Sizes. Tutorials in Quantitative Methods for Psychology, 3(2), 43-50. doi: 10.20982/tqmp.03.2.p043 
Notes

(1) Students' learning approach behaviour was measured using an actual learning task (Marton \& Säljö, 1976). Participants were asked to read a short passage and complete questions based on the reading. Participants were asked to answer six multiple-choice questions: two questions were answerable using deep learning approaches, two questions using surface learning behaviours and two questions that had two possible correct answers - one option that was indicative of a deep learning approach and the other that was indicative of a surface learning approach. In the current data, however, performance on this the comprehension task was not associated with any of the measured or manipulated variables. We calculated both "deep" and "surface" questions scores, as well as an omnibus "items correct" score. None of these scores were correlated with other variables in preliminary analyses and treating them as dependent variables in regression analysis yielded no significant findings. The absence of these expected relationships may be due to the fact that the questions accompanying the comprehension task chosen were potentially too simple for the audience $(>70 \%$ of respondents gave the "correct"/ "deep" response for 4 out of the 6 items). Given this restricted range of response, scores were uninformative of the learning approach taken, and the task was not analysed further.

(2) The course outline designed to communicate deep learning norms included large written assignments requiring students to think critically about the subject. These assignments were distributed throughout the semester in order to space out the workload (Tan, 1992). The course outline communicating surface learning behaviour had more assessment items compared to the deep course outline, was more MCQ exam focused and assessment tasks occurred close together (Scouller, 1998). The third 
course outline was a control. In this course outline, the educator norms were not clear. Therefore, this course outline consisted of a mix of MCQ exams and assignments, with some assignments being quite large and others small. For this course outline, some assessment tasks were quite spread out while others were close together. These course outline manipulations were pilot tested $(\mathrm{N}=27)$ prior to use, to ensure they communicated the norms intended and had face validity as course outlines.

(3) We also examined all interactions involving the leadership variable and found no significant effects. This is likely because the leadership scale, in our data, had very limited variance (most responses were clustered around the neutral point). Students likely had difficulty creating an impression of the course leader from the outlines. Future research might explore how this kind of imagined leader could be made more concrete. 
Social Identification and Normative Conflict: 33

\section{Table \& Figure Captions}

Table 1: Means, standard deviations and correlations of key variables

Table 2: Regression coefficients, predicting deep learning

Table 3: Regression coefficients, predicting surface learning

Figure 1: Conceptual model

Figure 2a: Form of the student norms $\mathrm{x}$ identification interaction: Control condition

Figure 2b: Form of the student norms x identification interaction: Surface educator norm condition

Figure 2c: Form of the student norms $\mathrm{x}$ identification interaction: Deep educator norm condition. 
Table 1: Means and Correlations

$\begin{array}{llllll}\text { Mean (SD) } & \text { Age } & \text { ID } & \text { DLA } & \text { SLA } & \text { SNORM }\end{array}$

Field of study Identification (ID)

$3.95(.51) \quad-.01 \quad-$

Deep Learning Approach (DLA)

$3.30(.58) \quad .08 \quad .39 * * \quad-$

Surface Learning Approach (SLA

$2.89(.57) \quad-.14 * \quad-.20 * * \quad-.46^{* *}$

Student Norms (SNORM)

$0.15(1.16) \quad .11 \quad .21 * * \quad .39 * * \quad-.42 * *$

Perceived Leadership (LEAD)

$3.39(.53) \quad-.09$

$\begin{array}{lll}.11 & .05 & -.05\end{array}$


Social Identification and Normative Conflict: 35

Table 2: Regression co-efficients, predicting deep learning

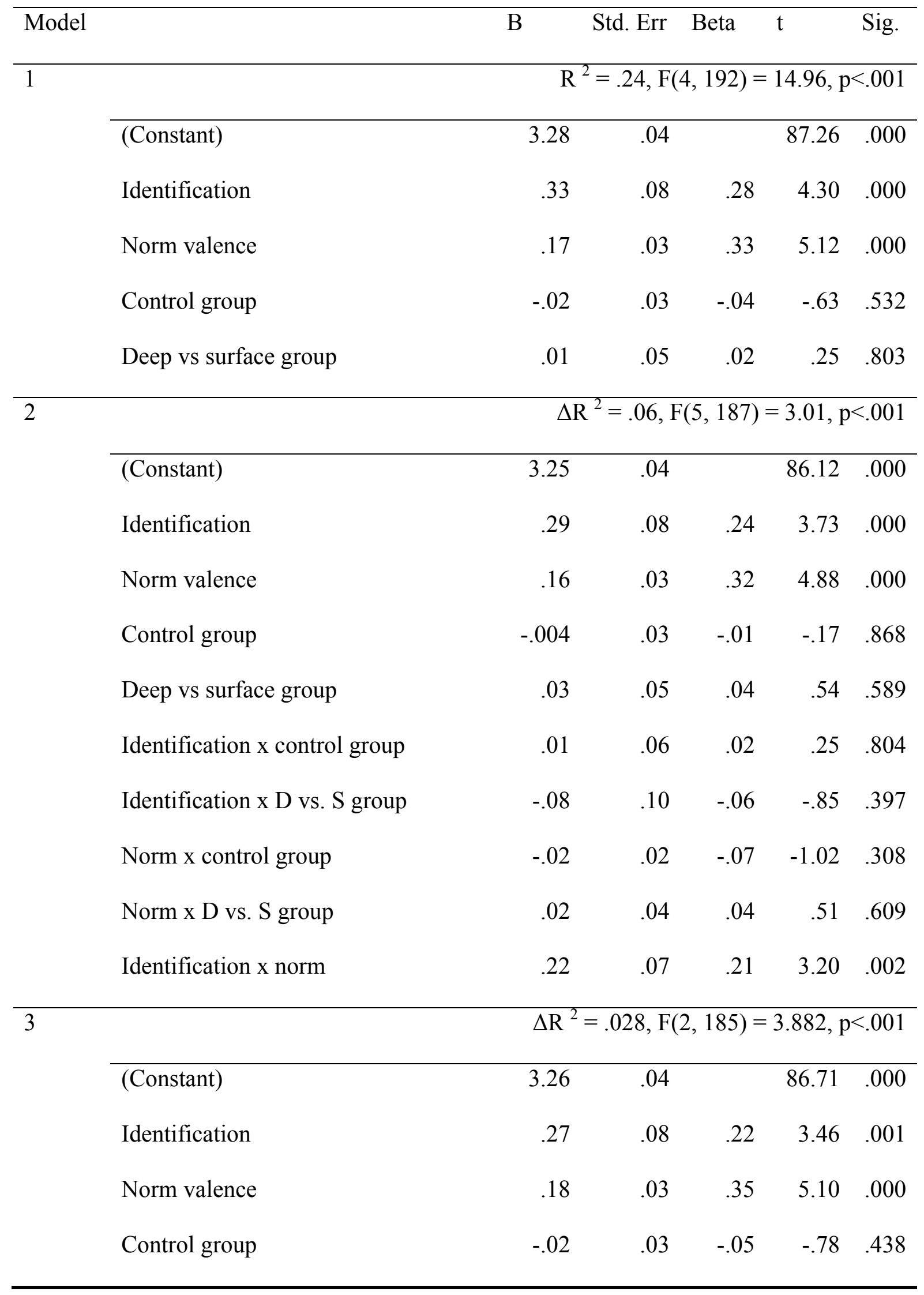


Social Identification and Normative Conflict: 36

\begin{tabular}{llllll}
\hline Deep vs surface group & .01 & .05 & .01 & .10 & .920 \\
Identification x control group & -.01 & .06 & -.02 & -.26 & .799 \\
Identification x D vs. S group & -.07 & .10 & -.05 & -.75 & .453 \\
Norm x control group & -.02 & .02 & -.04 & -.65 & .517 \\
Norm x D vs. S group & .03 & .04 & .04 & .61 & .544 \\
Identification x norm & .23 & .07 & .23 & 3.35 & .001 \\
Identification x norm x control & .12 & .05 & .17 & 2.55 & .012 \\
Identification x norm x D vs S group & .06 & .08 & .05 & .73 & .464 \\
\hline
\end{tabular}

Note $* p<.05, * * p<.01, * * * p<.001$ 
Social Identification and Normative Conflict: 37

Table 3: Regression co-efficients, predicting surface learning

\begin{tabular}{|c|c|c|c|c|c|c|}
\hline \multicolumn{2}{|c|}{ Model } & $\mathrm{B}$ & Std. Err & Beta & $\mathrm{t}$ & Sig. \\
\hline \multirow[t]{6}{*}{1} & \multicolumn{6}{|c|}{$\mathrm{R}^{2}=.18, \mathrm{~F}(4,192)=10.84, \mathrm{p}<.001$} \\
\hline & (Constant) & 2.91 & .04 & & 76.58 & .000 \\
\hline & Identification & -.15 & .08 & -.12 & -1.84 & .067 \\
\hline & Norm valence & -.19 & .03 & -.38 & -5.69 & .000 \\
\hline & Control group & .01 & .03 & .03 & .47 & .642 \\
\hline & Deep vs surface group & .01 & .05 & .02 & .34 & .734 \\
\hline \multirow[t]{11}{*}{2} & \multicolumn{6}{|c|}{$\Delta \mathrm{R}^{2}=.04, \mathrm{~F}(5,187)=1.80, \mathrm{p}<.001$} \\
\hline & (Constant) & 2.92 & \multicolumn{2}{|l|}{.04} & 75.45 & .000 \\
\hline & Identification & -.12 & .08 & -.10 & -1.52 & .131 \\
\hline & Norm valence & -.19 & .03 & -.38 & -5.55 & .000 \\
\hline & Control group & .003 & .03 & .009 & .13 & .897 \\
\hline & Deep vs surface group & -.002 & .05 & -.003 & -.05 & .961 \\
\hline & Identification $\mathrm{x}$ control group & -.06 & .06 & -.07 & -1.09 & .279 \\
\hline & Identification $\mathrm{x}$ D vs. S group & -.08 & .10 & -.06 & -.86 & .392 \\
\hline & Norm $\mathrm{x}$ control group & .005 & .03 & .02 & .21 & .835 \\
\hline & Norm x D vs. S group & .02 & .04 & .04 & .50 & 619 \\
\hline & Identification $\mathrm{x}$ norm & -.16 & .07 & -.17 & -2.35 & .020 \\
\hline 3 & \multicolumn{6}{|c|}{$\Delta \mathrm{R}^{2}=.01, \mathrm{~F}(2,185)=1.16, \mathrm{p}<.001$} \\
\hline & (Constant) & 2.92 & \multicolumn{2}{|l|}{.04} & 74.62 & .000 \\
\hline & Identification & -.10 & .08 & -.09 & -.13 & .209 \\
\hline & Norm valence & -.18 & .04 & -.37 & -5.03 & .000 \\
\hline & Control group & .01 & .03 & .03 & .41 & .683 \\
\hline
\end{tabular}


Social Identification and Normative Conflict: 38

\begin{tabular}{lccccc}
\hline Deep vs surface group & .01 & .05 & .02 & .24 & .807 \\
Identification x control group & -.06 & .06 & -.07 & -1.20 & .307 \\
Identification x D vs. S group & -.07 & .10 & -.05 & -.69 & .490 \\
Norm x control group & -.003 & .03 & -.008 & -.11 & .915 \\
Norm x D vs. S group & .04 & .04 & .06 & .80 & .426 \\
Identification x norm & -.18 & .07 & -.19 & -2.59 & .010 \\
Identification x norm x control & -.03 & .05 & -.04 & -.57 & .569 \\
Identification x norm x D vs S group & -.16 & .09 & -.10 & -1.31 & .192 \\
\hline
\end{tabular}

Note $* p<.05, * * p<.01, * * * p<.001$ 
Social Identification and Normative Conflict: 39

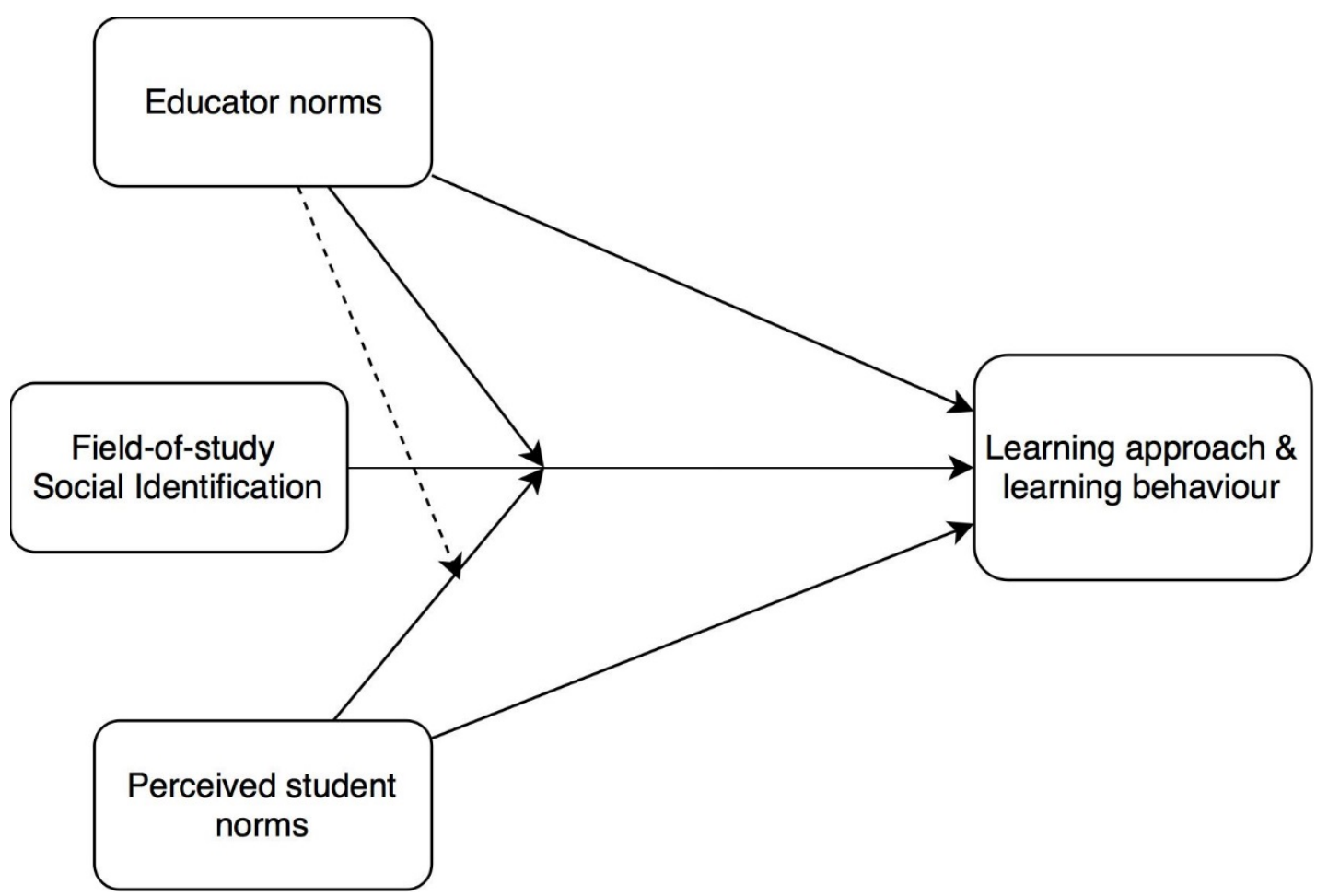

Figure 1: Conceptual Model 


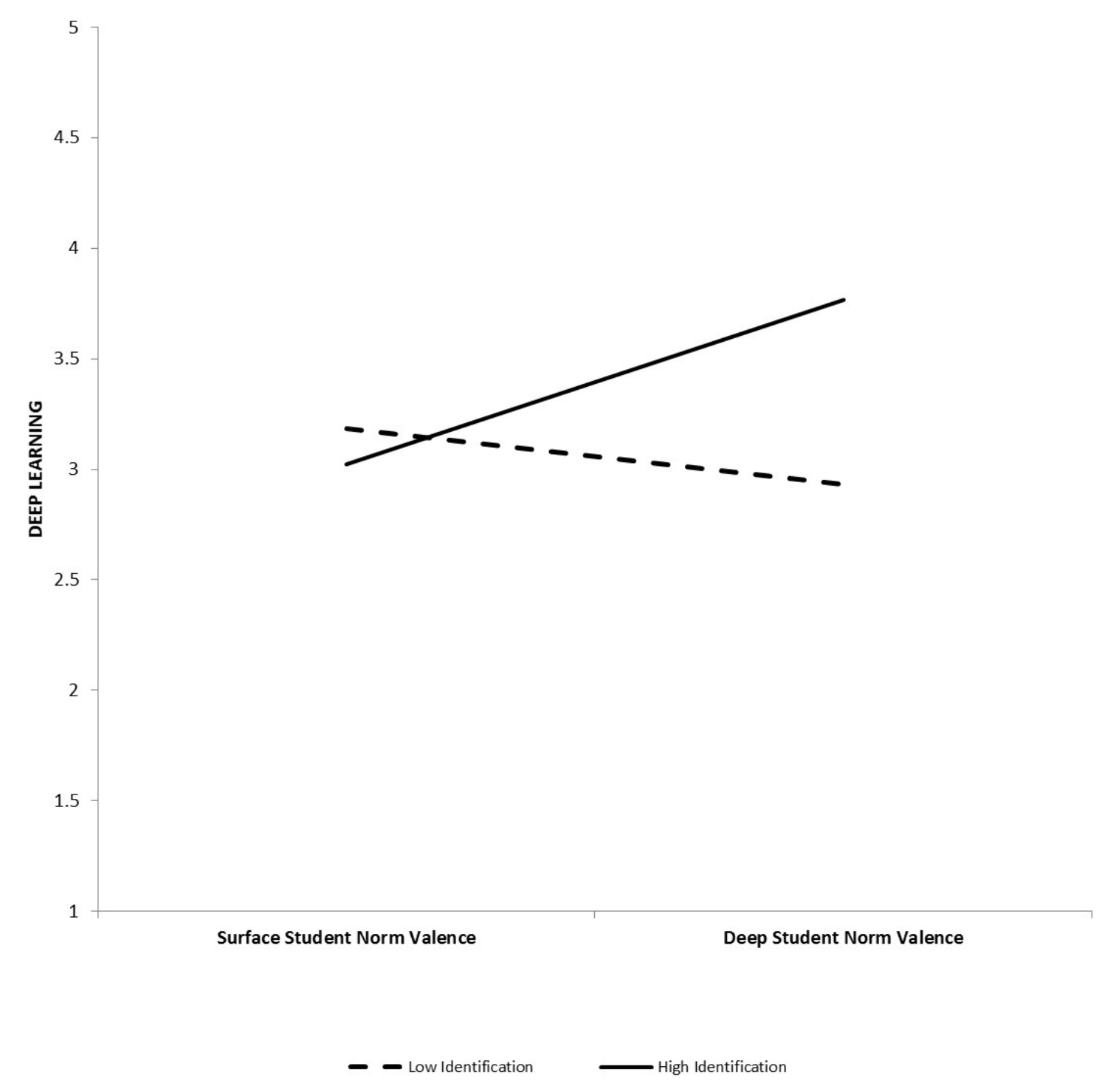

Figure 2a: Form of the student norms $x$ identification interaction: Control condition 
Social Identification and Normative Conflict: 41

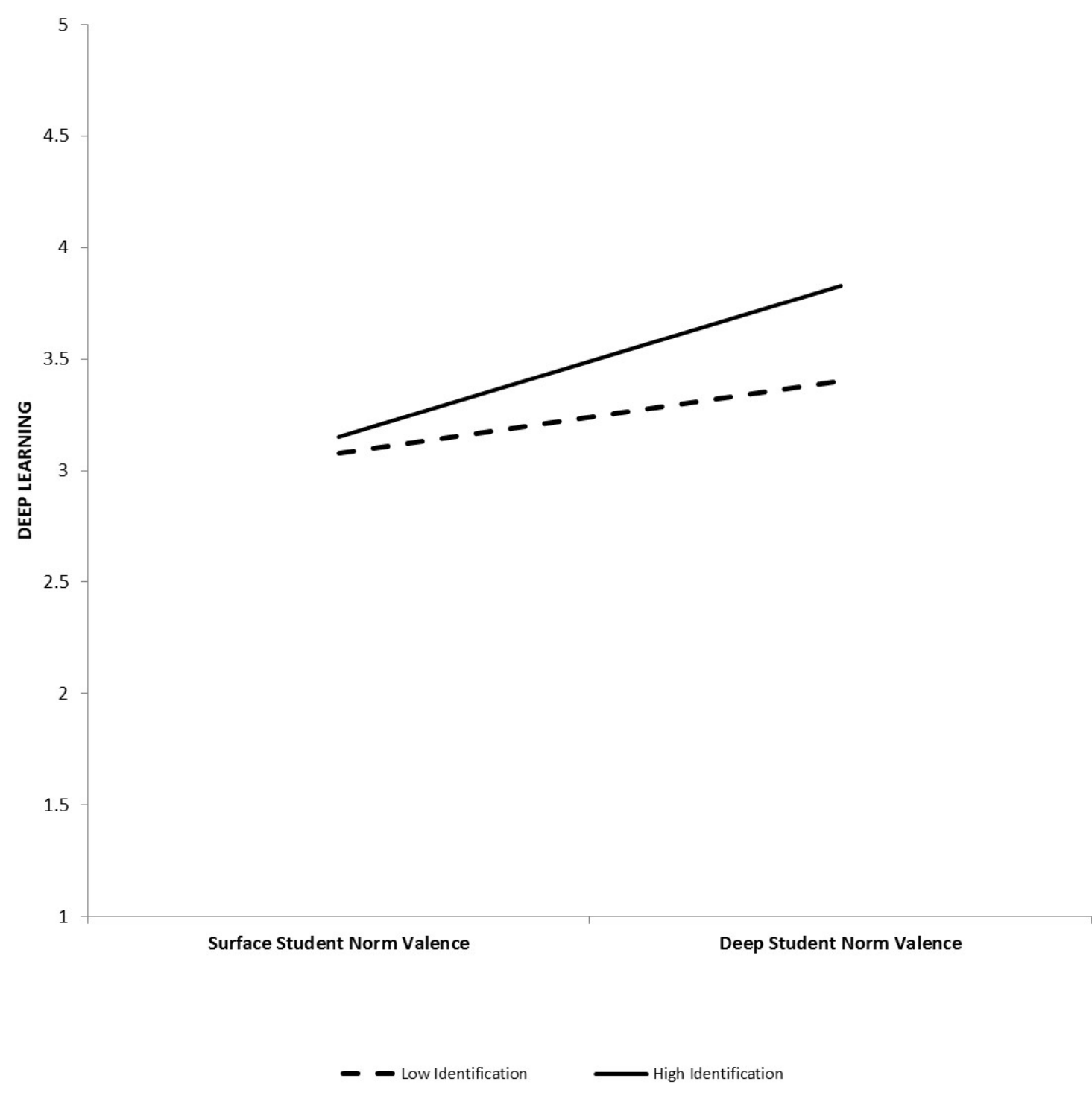

Figure 2b: Form of the student norms $x$ identification interaction: Surface educator norm condition 


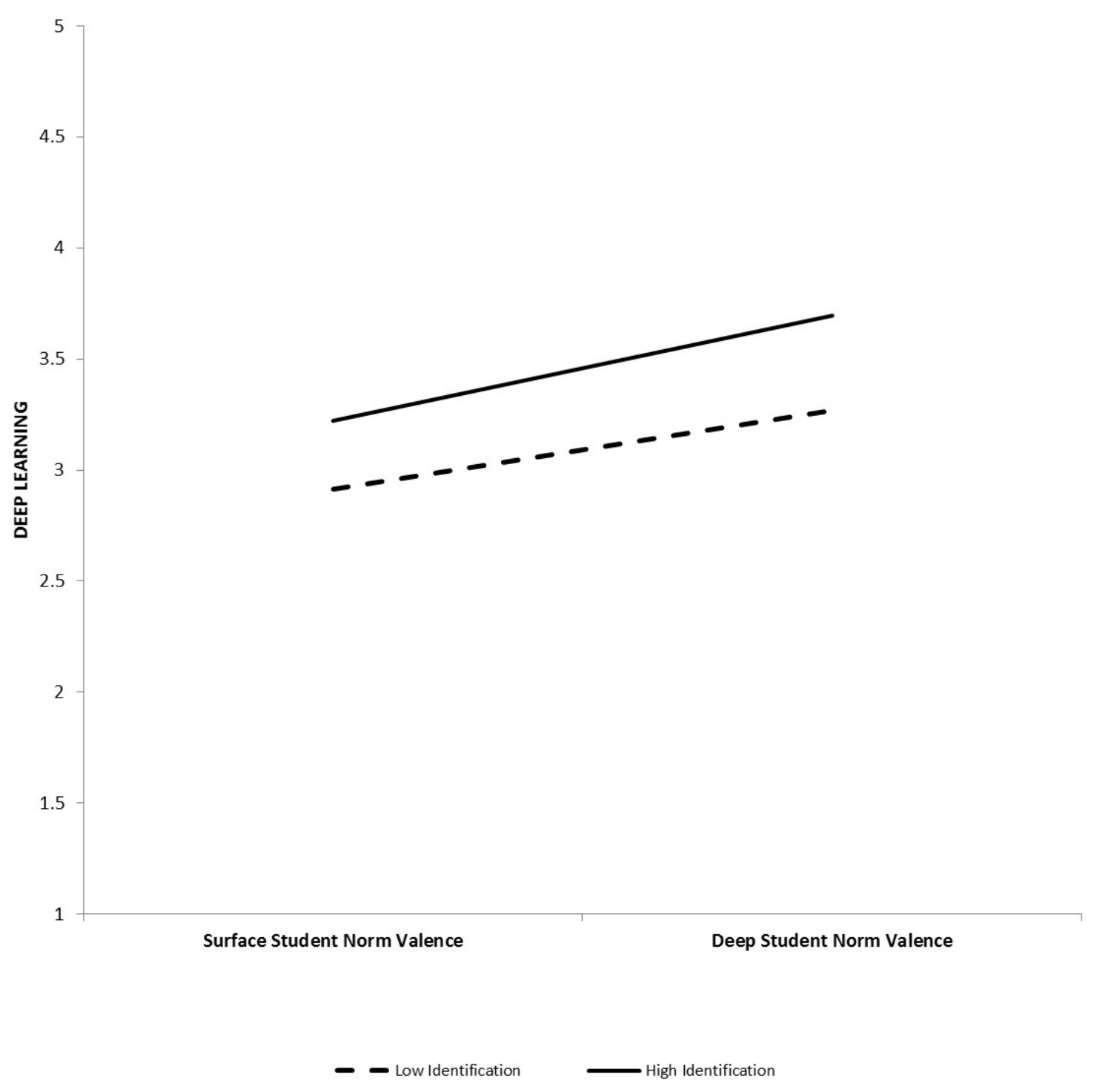

Figure 2c: Form of the student norms $x$ identification interaction: deep educator norm condition 